\title{
Living conditions and respiratory health in Walmer Township and Wells Estate, Port Elizabeth, South Africa
}

\author{
J Teare, ${ }^{1,2}$ MSc; N Naicker, ${ }^{2,3,4,5}$ FCPHM, MMed, PhD; C Swanepoel, ${ }^{2}$ MTech; R Street, ${ }^{1,3,6} \mathrm{PhD} ;$ A Mathee, ${ }^{1,2,3,4} \mathrm{PhD}$ \\ ${ }^{1}$ Environment and Health Research Unit, South African Medical Research Council, Johannesburg, South Africa \\ ${ }^{2}$ Department of Environmental Health, School of Behavioural and Lifestyle Sciences, Faculty of Health Sciences, Nelson Mandela University, \\ Port Elizabeth, South Africa \\ ${ }^{3}$ Department of Environmental Health, Faculty of Health Sciences, University of Johannesburg, South Africa \\ ${ }^{4}$ School of Public Health, Faculty of Health Sciences, University of the Witwatersrand, Johannesburg, South Africa \\ ${ }^{5}$ Epidemiology and Surveillance Section, National Institute of Occupational Health, National Health Laboratory Service, Johannesburg, \\ South Africa \\ ${ }^{6}$ Department of Occupational and Environmental Health, School of Nursing and Public Health, University of KwaZulu-Natal, Durban, South Africa
}

Corresponding author: J Teare (june.teare@mrc.ac.za)

\begin{abstract}
Background. Many impoverished communities in South Africa (SA) simultaneously face multiple preventable socioenvironmental hazards associated with elevated burdens of ill health. One such hazard is failure to institute effective buffer zones between human settlements and point sources of pollution such as airports and industrial zones.

Objectives. To gather information on living conditions, housing quality and health status in two poor communities in the SA coastal industrial city of Port Elizabeth.

Methods. The study was undertaken in Walmer Township, situated in close proximity to Port Elizabeth International Airport, and Wells Estate, which borders two industrial sites. Approximately 120 households were randomly selected from each study site. Following written informed consent, information on the neighbourhood environment and housing conditions was collected through administration of a structured questionnaire.

Results. The two study sites were similar in respect of household language, income, education, high levels of debt servicing and high reliance on social grants. Relative to Walmer Township, higher levels of indoor dust and bad odours in the neighbourhood were reported in Wells Estate, as were higher rates of selected respiratory ill-health symptoms. Upper respiratory tract symptoms were significantly associated with reports of high levels of indoor dust, while lower respiratory tract symptoms were significantly associated with low income, overcrowding, and having a young child in the household.

Conclusions. The study highlights a scenario of a triple environmental hazard to health in the study communities: (i) poverty; (ii) poorquality housing; and (iii) lack of an effective buffer zone between the study communities and local point sources of pollution. Respiratory ill-health conditions were significantly associated with poverty, household composition and living conditions.
\end{abstract}

S Afr Med J 2021;111(1):33-39. https://doi.org/10.7196/SAMJ.2021.v111i1.14655

Healthy housing is a fundamental pillar of good health in terms of its World Health Organization (WHO) definition as a state of complete physical, mental and social wellbeing, and not just the absence of disease. ${ }^{[1]}$ Healthy housing is associated with 'a feeling of home' and also refers to the quality and role of the physical structure in enabling health, including aspects related to shelter from the elements, access to safe sources of energy and healthy indoor and ambient air, access to sufficient quantities of safe water, thermal comfort, absence of dampness and mould, and protection from pollutants, injury hazards and pests. Healthy housing also relates to local availability of education and health services, green space, active public transport options and protection from waste and pollution. ${ }^{[2]}$

The location of housing in close proximity to sites of industrial pollution may cause preventable public exposure to pollutants in air, soil and water, with concomitantly elevated burdens of ill health, as indicated by numerous studies conducted in various parts of the world and in varying population groups. For example, a study undertaken in Oman showed that living close to an industrial park was associated with elevated levels of acute respiratory disease, asthma, conjunctivitis and dermatitis. ${ }^{[3]}$ The risks of ill health were highest in older people and those of lower socioeconomic status. In
Spain, living $<2.5 \mathrm{~km}$ from certain industries has been associated with an excess risk of childhood leukaemia. ${ }^{[4]}$ Researchers in Pueblo, Colorado (USA), have also shown that certain pollutant exposures may incur ill-health effects decades after the cessation of industrial activity ${ }^{[5]}$

Poor-quality housing, polluted living environments, and poor economic and social conditions (such as unemployment, uncertain employment and limited education) may independently exert detrimental health effects on affected communities. ${ }^{[6]}$ In South Africa (SA), economic pressures underpinned by poor economic growth, high levels of unemployment, increasing consumer prices for energy and food, and household dependence on credit are some of the factors driving high levels of poverty. In 2015, $>55 \%$ of South Africans were living in poverty, most of whom were black Africans, females, children, those with little or no education, and those living in Eastern Cape or Limpopo provinces. ${ }^{[7]}$

Exposure to toxic substances in and around dwellings is a particular concern given the amount of time spent in the home environment. In well-resourced countries, people may spend $~ 70 \%$ of their time at home. In poorly resourced countries, where unemployment rates may be high and where relatively large proportions of households generate 
livelihoods through cottage industries, the proportion of the day spent at home may be higher still, especially among childminders, children, the elderly, and people with preexisting ill-health conditions. ${ }^{[1]}$

The SA city of Port Elizabeth is located on the coast of Eastern Cape Province. Port Elizabeth houses one of the country's busiest seaports, the deep-water Port of Ngqura, two large industrial areas and several large motor vehicle assembly plants. Despite the potential for Port Elizabeth industrial operations to be a source of public exposure to a wide range of associated pollutants, there is a dearth of environmental and health information on local communities, especially in relatively impoverished Port Elizabeth neighbourhoods or townships located in close proximity to sites of pollution.

\section{Objectives}

To investigate the living conditions and health status of communities in two such townships: Walmer Township and Wells Estate. The findings provide important insights into local environmental and health concerns and needs in the two communities, and a baseline against which the impacts of ongoing industrial development and emissions (which may increase in coming years in the light of plans for local industrial expansion), as well as any interventions which may be implemented, could be measured.

\section{Methods}

In May 2016, the South African Medical Research Council and Nelson Mandela University, together with the Nelson Mandela Bay Municipality, embarked on household surveys in two low-income Port Elizabeth neighbourhoods, namely Walmer Township and Wells Estate. Data from the 2011 SA census indicate that $\sim 19000$ people lived in each of the study sites. ${ }^{[8]}$ Walmer Township (or Gqebera, as it is known locally) is one of the oldest townships in Port Elizabeth and is currently flanked along its southern border by the city's airport (Fig. 1).

Wells Estate is located $\sim 20 \mathrm{~km}$ from the centre of the city of Port Elizabeth, and close to two major industrial zones (Fig. 2). The Markman Industrial Area is the older of the two, and houses an abattoir, a tannery, and cement, steel and brick manufacturers, among other industries. The more recently constructed Coega Industrial Development Zone (Coega IDZ) lets space to a range of industries, including manufacturers of vehicles, wind towers and cement, a steel mill, aquaculture, cold storage and processing of agricultural produce. The Coega IDZ also

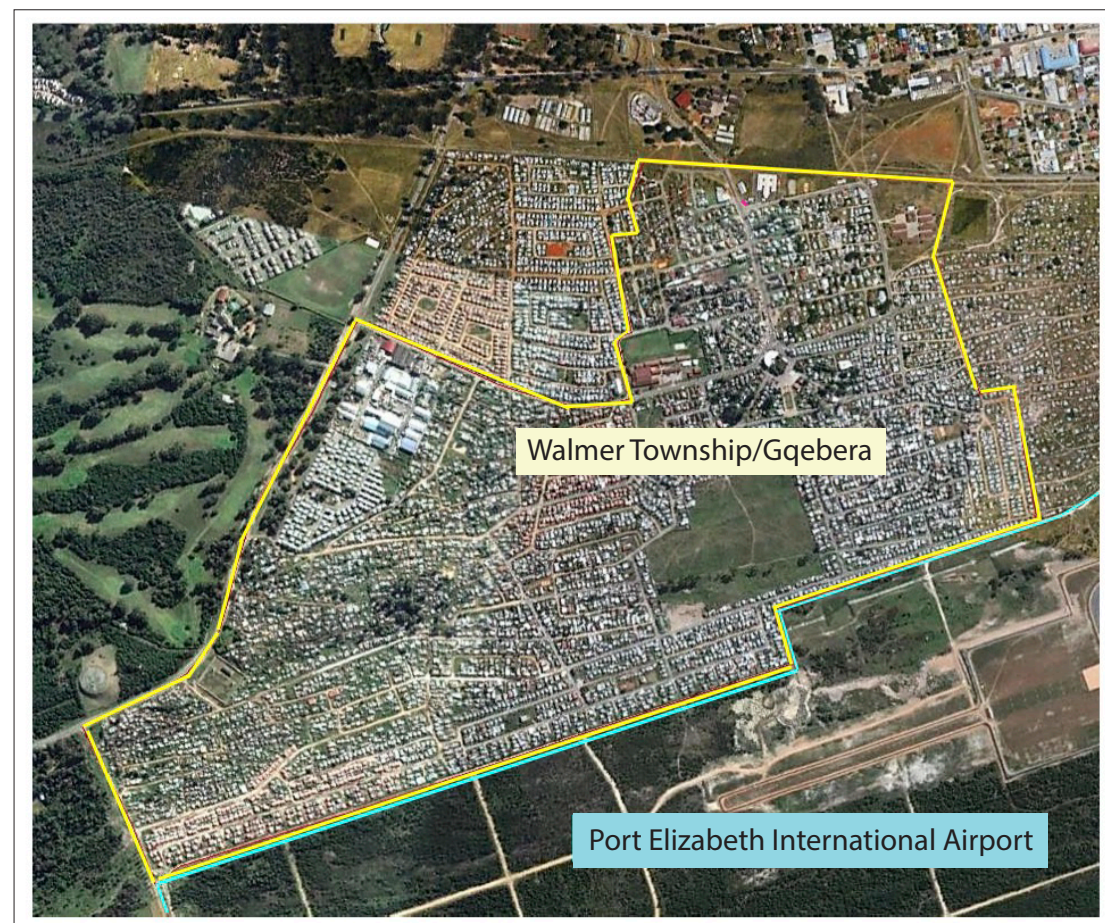

Fig. 1. Walmer Township/Gqebera and the adjacent airport (adapted from Google Earth Map data 2016, AfriGIS (Pty) Ltd, Google Imagery 2016).

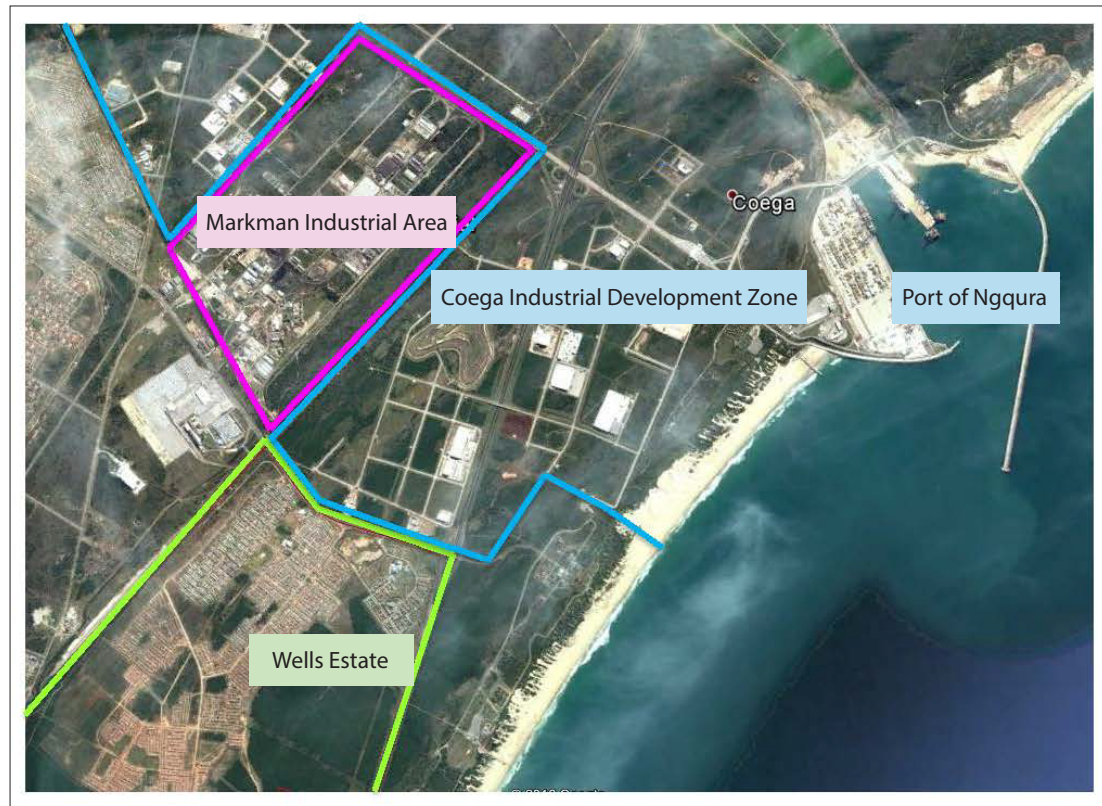

Fig. 2. Map showing the location of Wells Estate (boundaries outlined in green) in relation to Coega Industrial Development Zone (approximate southern boundaries shown in blue) and Markman Industrial Area (magenta borders) (adapted from Google Earth Map data 2016, AfriGIS (Pty) Ltd, Google Imagery 2016).

has the infrastructure to support nuclear, conventional and renewable energy projects, as well as an oil refinery. Forming part of the Coega IDZ is the deep-water Port of Ngqura, the third-busiest container port in SA. ${ }^{[9]}$ There are plans in place to expand the portfolio of industrial operations in the Coega IDZ. Wells Estate was established in
2001, when low-cost housing was built for 300 families that had been displaced in order to construct the Coega IDZ and the Port of Ngqura. ${ }^{[10,11]}$

Ethical approval for the study was obtained from Nelson Mandela University prior to commencement (ref. no. H14-HEAENV-001). Confidentiality and privacy 
were ensured by removal of all identifiers, such as names of the participants, and allocation of a unique study number to each study participant.

Approximately 120 households per site were randomly selected for inclusion in the study using town planning maps. In 2016, following written informed consent, one household member of at least 18 years of age was interviewed to obtain information on factors including household sociodemographic status, perceptions of the living environment and housing conditions, and health status. Responses were entered on site into a hand-held digital device preloaded with the study questionnaire. The software and services of Mobenzi Researcher (https://www.mobenzi.com/\#key-features), a data management system, provided real-time access to uploaded data, allowing the study co-ordinator to monitor data collection activities.

Data were analysed using Stata SE, version 15 (StataCorp, USA). Categorical data were described using frequencies, proportions and percentages. Continuous data were presented as means, medians and measures of spread. The outcome variables were upper and lower respiratory tract infections. Upper respiratory tract infections were defined as a wet or dry cough, runny or blocked nose, fever and chills, chest pain, earache, headaches, rapid breathing, sore throat, sneezing or teary/watery eyes, experienced by participants or household members during the 2-week period prior to the interview. Lower respiratory tract infections were bronchitis and pneumonia. Univariate analyses for sociodemographic and environmental characteristics and respiratory health outcomes (acute upper and lower respiratory tract infections) in each site were compared using $\chi^{2}$ tests. The level of significance was taken at $p<0.05$. For the multiple regression models, new binary variables were created for upper and lower respiratory tract infections. Participants were considered to have an upper respiratory tract infection if they presented with one or more symptoms. Participants who had bronchitis or pneumonia diagnosed were recorded as having a lower respiratory tract infection. Independent variables (sociodemographic and environmental factors) were included in the regression model if the $p$-value was $<0.05$, and adjusted odds ratios (aORs) were calculated.

\section{Results}

The study response rates in Walmer Township and Wells Estate were $68 \%$ and $85 \%$, respectively. Lack of an eligible respondent at home at the time of the field visit was the main reason for not being included in the study. In Walmer Township, political unrest prevented access to some of the selected study dwellings. While the mean age of the head of the household differed significantly $(p=0.005)$, the two communities were similar in respect of a range of socioeconomic and demographic factors (Table 1). Most household members had been born in the Eastern Cape, the province in which the city of Port Elizabeth is located. The vast majority spoke isiXhosa at home. Low proportions of household heads in both communities had achieved tertiary education (12\% in Walmer Township and $14 \%$ in Wells Estate). More than one-third of adult household members in both communities were unemployed; consequently, average monthly household incomes were low and there was a high level of reliance on state financial grants (predominantly child support grants and oldage pensions). Access to medical insurance was also low. However, more households in Walmer Township relative to Wells Estate had been able to save money $(p=0.04)$.

The median dwelling age was relatively high in Walmer Township (23 years) compared with Wells Estate (13 years). Dwellings in both townships had a median of five rooms, and households comprised a median of four people. Electricity was the main fuel used for cooking in both communities (96\%), and 37\% and 38\% of households in Walmer Township and Wells Estate, respectively, included someone who smoked (Table 1).

To generate additional income, $33 \%$ (27/81) of Walmer Township households operated at least one cottage industry at home, of which $44 \%(12 / 27)$ involved activities potentially associated with toxic metals, for example spray painting, hairdressing and car repairs. The remaining 15 households generated an income through activities such as needlework, photography, painting and tiling. In Wells Estate, $\sim 18 \%(18 / 102)$ of households operated at least one cottage industry, of which $50 \%(9 / 18)$ were metal-related (i.e. making jewellery, repairs to electrical appliances and hairdressing). The remaining households were involved in money lending, miscellaneous sales, beadwork and laundry services.

Fig. 3 shows the top-ranked monthly household expenditures. It can be seen that in both sites the biggest share of household expenditure was on food supplies, followed by debt servicing and education. In general, household expenditure was higher in Walmer Township than Wells Estate, apart from transportation, rent/bond payments and medical expenses, on which Wells Estate residents spent more (although not significantly so).

Structural conditions of dwellings in Walmer Township and Wells Estate as reported by the respondents are shown in Fig. 4. The presence of cracks in the walls of dwellings predominated in both study sites (>85\%), followed by peeling paint (indoors and outdoors), leaking roofs and broken windows.

Table 2 sets out the responses given when interviewees were asked about their perceptions of selected aspects of the local environment, as well as self-reported ill-health conditions among household members. More respondents in Wells Estate relative to Walmer Township reported major problems with indoor dust ( $p=0.006)$, as well as with odours $(p=0.025)$ in the neighbourhood. Similarly, in terms of ill-health symptoms, there was a higher level of reports of 'wet cough' $(p=0.045)$, rapid breathing $(p=0.026)$, sneezing $(p=0.024)$ and teary/watery eyes $(p=0.012)$ in Wells Estate relative to Walmer Township. Self-reported levels of pneumonia, bronchitis and tuberculosis were similar in the two communities.

The results of univariate analyses to explore relationships between risk factors and health status are set out in Table 3. Self-reported pneumonia and bronchitis (lower respiratory tract infections) were significantly associated with low income levels (odds ratio (OR) 0.791; $p=0.056$ ), having a child aged $<5$ years in the household (OR 8.514; $p<0.001$ ), living in a dwelling with cracks in the walls (OR 3.01; $p=0.016$ ) and overcrowding (OR 2.853; $p=0.004$ ). After adjusting for potential confounding factors, having a child aged $<5$ years in the household (aOR 7.292; $p<0.001$ ) remained significantly associated with elevated levels of bronchitis and pneumonia. The wide confidence intervals are probably due to the small sample size, and this result should be viewed with caution. Perceptions of dust inside dwellings, cracks in walls, bad odours in the neighbourhood, air pollution in the neighbourhood, and overcrowding in the dwelling and neighbourhood as 'major' problems were significant in the univariate analyses. However, only air pollution in the neighbourhood retained a significant association with upper respiratory infections (aOR 2.031; $p=0.051$ ) after adjusting for confounding factors.

\section{Discussion}

This is the first detailed description of the living conditions and health status of two poor communities in one of SA's few coastal industrial cities. The results indicate high levels of poverty in 


\begin{tabular}{|c|c|c|c|}
\hline Variable & $\begin{array}{l}\begin{array}{l}\text { Walmer Township } \\
(N=81 \text { respondents })^{\dagger}\end{array} \\
\end{array}$ & $\begin{array}{l}\text { Wells Estate } \\
(N=102 \text { respondents })^{\dagger}\end{array}$ & $p$-value \\
\hline Age of household head (years) & & & $0.005^{*}$ \\
\hline Mean & 55.6 & 49.1 & \\
\hline Median & 57 & 49 & \\
\hline Range & $18-95$ & $21-90$ & \\
\hline Sex of household head, $n(\%)$ & & & 0.51 \\
\hline Male & $30(37)$ & $44(43)$ & \\
\hline Female & $51(63)$ & $58(57)$ & \\
\hline Province of birth, $n$ (\%) & & & 0.20 \\
\hline Eastern Cape & $75(99)$ & $86(96)$ & \\
\hline Elsewhere & $1(1)$ & $4(4)$ & \\
\hline Main language spoken in household, $n$ (\%) & & & 0.58 \\
\hline isiXhosa & $79(98)$ & $98(96)$ & \\
\hline Other & $2(2)$ & $4(4)$ & \\
\hline Highest level of education achieved by household head, $n$ (\%) & & & 0.87 \\
\hline None & $6(7)$ & $9(9)$ & \\
\hline Primary school & $23(30)$ & $30(29)$ & \\
\hline Secondary school & $42(52)$ & $49(48)$ & \\
\hline Tertiary education & $10(12)$ & $14(14)$ & \\
\hline \multicolumn{4}{|l|}{ Households with children aged $<5$ years, $n(\%)$} \\
\hline One or more children & $32(40)$ & $39(38)$ & 0.86 \\
\hline Monthly household income ${ }^{\S}$ excluding grants and pensions, $n(\%)$ & & & 0.43 \\
\hline$\leq$ ZAR1 000 & $34(42)$ & $51(50)$ & \\
\hline ZAR1 $001-5000$ & $34(42)$ & $40(39)$ & \\
\hline >ZAR5 000 & $13(16)$ & $11(11)$ & \\
\hline \multicolumn{4}{|l|}{ Households receiving government grants, $n$ (\%) } \\
\hline At least one grant (includes old-age pension, disability grant, child support grant) & $62(77)$ & $79(78)$ & 0.89 \\
\hline Old-age pension & $34(42)$ & $38(37)$ & 0.52 \\
\hline Disability grant & $10(12)$ & $9(9)$ & 0.44 \\
\hline Child support grant & $34(42)$ & $56(55)$ & 0.08 \\
\hline \multicolumn{4}{|l|}{ Money saved in bank/stokvel, $n(\%)$} \\
\hline Yes & $32(40)$ & $26(25)$ & $0.04^{*}$ \\
\hline \multicolumn{4}{|l|}{ Access to medical aid, $n$ (\%) } \\
\hline Yes & $11(14)$ & $16(16)$ & 0.69 \\
\hline \multicolumn{4}{|l|}{ Households with electricity, $n(\%)$} \\
\hline Use electricity for cooking & $78(96)$ & $97(96)$ & 0.93 \\
\hline Use electricity for heating water & $75(93)$ & $95(94)$ & 0.69 \\
\hline \multicolumn{4}{|l|}{ Households with at least one smoker, $n(\%)$} \\
\hline Yes & $30(37)$ & $38(38)$ & 0.94 \\
\hline Main weekly activities of household members, $n$ (\%) & $N=385^{9}$ & $N=419$ & \\
\hline Full-time job & $53(14)$ & $48(11)$ & \\
\hline Part-time job or informal job & $48(13)$ & $59(14)$ & \\
\hline Unemployed or housewife/husband & $149(39)$ & $140(33)$ & \\
\hline At tertiary educational institution & $14(4)$ & $4(1)$ & \\
\hline At school & $77(20)$ & $119(28)$ & \\
\hline At crèche & $18(5)$ & $29(7)$ & \\
\hline Retired & $12(3)$ & $8(2)$ & \\
\hline Other & $14(4)$ & $12(3)$ & \\
\hline 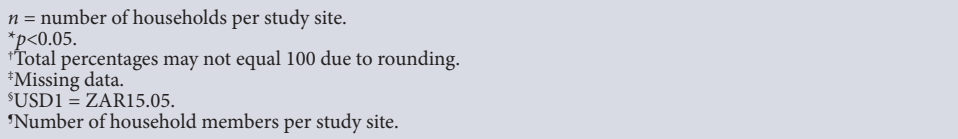 & & & \\
\hline
\end{tabular}

both communities, evidenced by high unemployment levels, low household incomes, heavy reliance on state support, low savings capacity and limited affordability of medical aid. Unemployment levels in Walmer Township and Wells Estate were higher than provincial and national unemployment rates. ${ }^{[12]} \mathrm{A}$ further indicator of the degree of poverty in both Walmer Township and Wells Estate was that during the year of fieldwork, debt servicing was the secondranked expenditure item, which inevitably constitutes a further drain 
Table 2. Perceptions of dwelling and neighbourhood conditions and self-reported respiratory health outcomes

\begin{tabular}{|c|c|c|c|c|}
\hline Variable & $\begin{array}{l}\text { Total }(N=183 \\
\text { respondents), }{ }^{\dagger} n(\%)\end{array}$ & $\begin{array}{l}\text { Walmer Township }(N=81 \\
\text { respondents) }{ }^{\dagger} n(\%)\end{array}$ & $\begin{array}{l}\text { Wells Estate }(N=102 \\
\text { respondents) }{ }^{\dagger} n(\%)\end{array}$ & $p$-value \\
\hline \multicolumn{5}{|c|}{ Perceptions of neighbourhood and dwelling conditions } \\
\hline \multicolumn{5}{|c|}{ The following is a moderate or major problem } \\
\hline Dust in the dwelling & $125(68.3)$ & $47(58.0)$ & $78(76.5)$ & $0.006^{*}$ \\
\hline Mould or fungus in the dwelling & $104(56.8)$ & $46(56.8)$ & $58(56.9)$ & 0.931 \\
\hline Dampness in the dwelling & $85(46.4)$ & $41(51.0)$ & $44(43.1)$ & 0.340 \\
\hline Cracked walls & $157(85.8)$ & $69(85.2)$ & $88(86.3)$ & 0.705 \\
\hline Leaking water pipes & $66(36.1)$ & $30(37.0)$ & $36(35.3)$ & 0.846 \\
\hline Poor ventilation in the dwelling & $45(24.6)$ & $22(27.2)$ & $23(22.5)$ & 0.490 \\
\hline Overcrowding in the dwelling & $51(27.9)$ & $27(33.3)$ & $24(23.5)$ & 0.153 \\
\hline Operating a cottage industry & $18(9.8)$ & $10(12.3)$ & $8(7.8)$ & 0.310 \\
\hline Bad odours in the neighbourhood & $113(61.7)$ & $43(53.1)$ & $70(68.6)$ & $0.025^{*}$ \\
\hline Air pollution in the neighbourhood & $111(60.6)$ & $44(54.3)$ & $67(65.7)$ & 0.099 \\
\hline Overcrowding in the neighbourhood & $78(42.6)$ & $38(46.9)$ & $40(39.2)$ & 0.322 \\
\hline \multicolumn{5}{|c|}{$\begin{array}{l}\text { Self-reported acute and chronic ill-health status } \\
\text { of household members }\end{array}$} \\
\hline URTIs & $120(65.6)$ & $49(60.5)$ & $71(69.6)$ & 0.197 \\
\hline Wet cough & $76(41.5)$ & $27(33.3)$ & $49(48)$ & $0.045^{*}$ \\
\hline Dry cough & $88(48.1)$ & $45(55.6)$ & $43(42.2)$ & 0.072 \\
\hline Runny/blocked nose & $97(53.0)$ & $42(51.9)$ & $55(53.9)$ & 0.781 \\
\hline Fever and chills & $143(78.1)$ & $62(76.5)$ & $81(79.4)$ & 0.641 \\
\hline Chest pain & $70(38.3)$ & $25(30.9)$ & $45(44.1)$ & 0.067 \\
\hline Earache & $32(17.5)$ & $12(24.7)$ & $20(19.6)$ & 0.397 \\
\hline Headaches & $119(65.0)$ & $48(59.3)$ & $71(69.6)$ & 0.145 \\
\hline Rapid breathing & $36(19.7)$ & $10(12.3)$ & $26(25.5)$ & $0.026^{*}$ \\
\hline Sore throat & $42(22.9)$ & $22(27.2)$ & $20(19.6)$ & 0.228 \\
\hline Sneezing & $94(51.4)$ & $34(41.9)$ & $60(58.8)$ & $0.02^{*}$ \\
\hline Teary/watery eyes & 73 (39.9) & $24(29.6)$ & $49(48.0)$ & $0.012^{*}$ \\
\hline LRTIs & $100(54.6)$ & $45(55.6)$ & $55(53.9)$ & 0.825 \\
\hline Bronchitis & $17(9.3)$ & $8(9.9)$ & $9(8.8)$ & 0.807 \\
\hline Pneumonia & $93(50.8)$ & $43(53.1)$ & $50(49.0)$ & 0.585 \\
\hline Tuberculosis & $8(4.4)$ & $4(4.9)$ & $4(3.9)$ & 0.530 \\
\hline
\end{tabular}

on already constrained household financial resources. The WHO Commission on Social Determinants of Health (CSDH) has described poverty and poor living standards as powerful determinants of ill health, overwhelming the health impact of lifestyles and medical care, for example. ${ }^{[13,14]}$ Within the home setting, the operation of cottage industries associated with pollutant emissions, such as spray painting and electrical appliance repairs, while contributing to household coffers, constitutes an insidious cause for public health concern. The risks are highest for young children, the elderly, and those who are unemployed or have pre-existing ill-health conditions, who may spend most of their time in the home environment. ${ }^{[15]}$

Apart from their poverty, a second layer of health vulnerability for the two study communities arises from the poor quality of their housing, including high levels of damp and fungal infestations, cracked walls, peeling paint, leaking roofs and water pipes, poor ventilation, overcrowding, widespread perceptions of local air pollution and bad odours in the neighbourhood, each of which is associated with ill-health conditions. In recognition of the powerful role of housing quality in health, the WHO recently updated its guidelines for healthy housing, especially in the light of climate change. ${ }^{[1]}$ The new WHO housing and health guidelines build on earlier WHO guidelines on indoor air and water quality, for example, as well as on evidence emerging from the $\mathrm{WHO} \mathrm{CSDH}$, which emphasise the role of living conditions in health status. ${ }^{[16]} \mathrm{A}$ key question asked by the WHO CSDH was why we keep treating people only to send them back to the conditions that caused their ill health in the first place. This question is valid in respect of housing quality in Walmer Township and Wells Estate, and should be considered by local health, housing, trade and industry and financial sectors.

A third layer of preventable environmental health vulnerability in Walmer Township and Wells Estate is brought to bear by planning decisions to locate human settlements in close proximity to point sources of pollution, in this case the Port Elizabeth airport $(\sim 200 \mathrm{~m}$ from Walmer Township) and the Markman and Coega industrial areas ( $\sim 750 \mathrm{~m}$ and $120 \mathrm{~m}$, respectively, from Wells Estate). While detailed air, water and soil quality studies have not yet been undertaken in the study areas, significantly elevated perceptions of indoor dust and air pollution in Wells Estate (located very close to the Markman and Coega industrial areas) should be heeded, and it is hoped will catalyse a proactive programme of investigation and concomitant intervention. Proximity to, or exposures from, sources of pollution are strongly associated with ill health, compromised quality of life and shortened life expectancy. Apart from noise, airports 


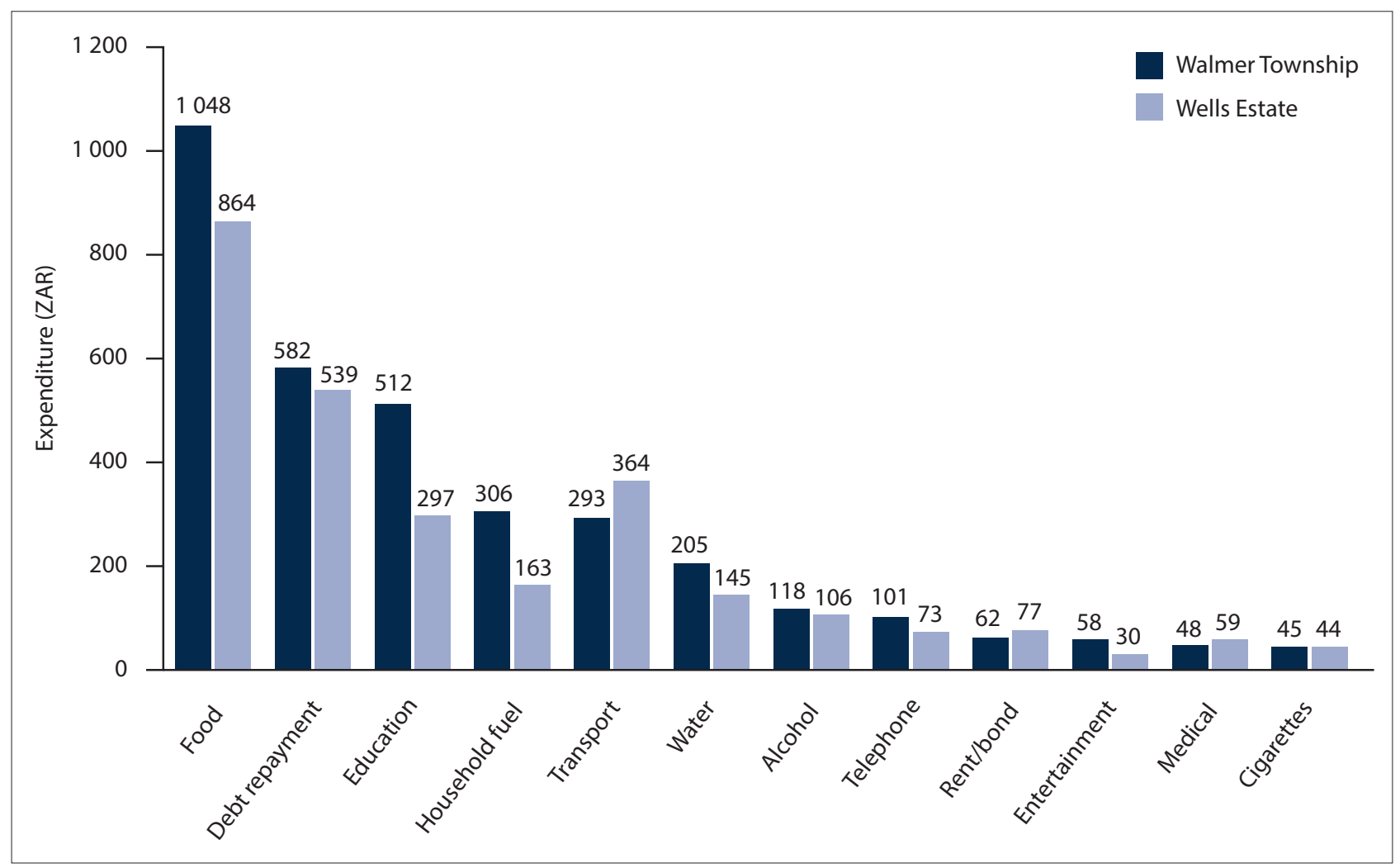

Fig. 3. Average monthly household expenditure in the study population (USD1 = ZAR15.05).

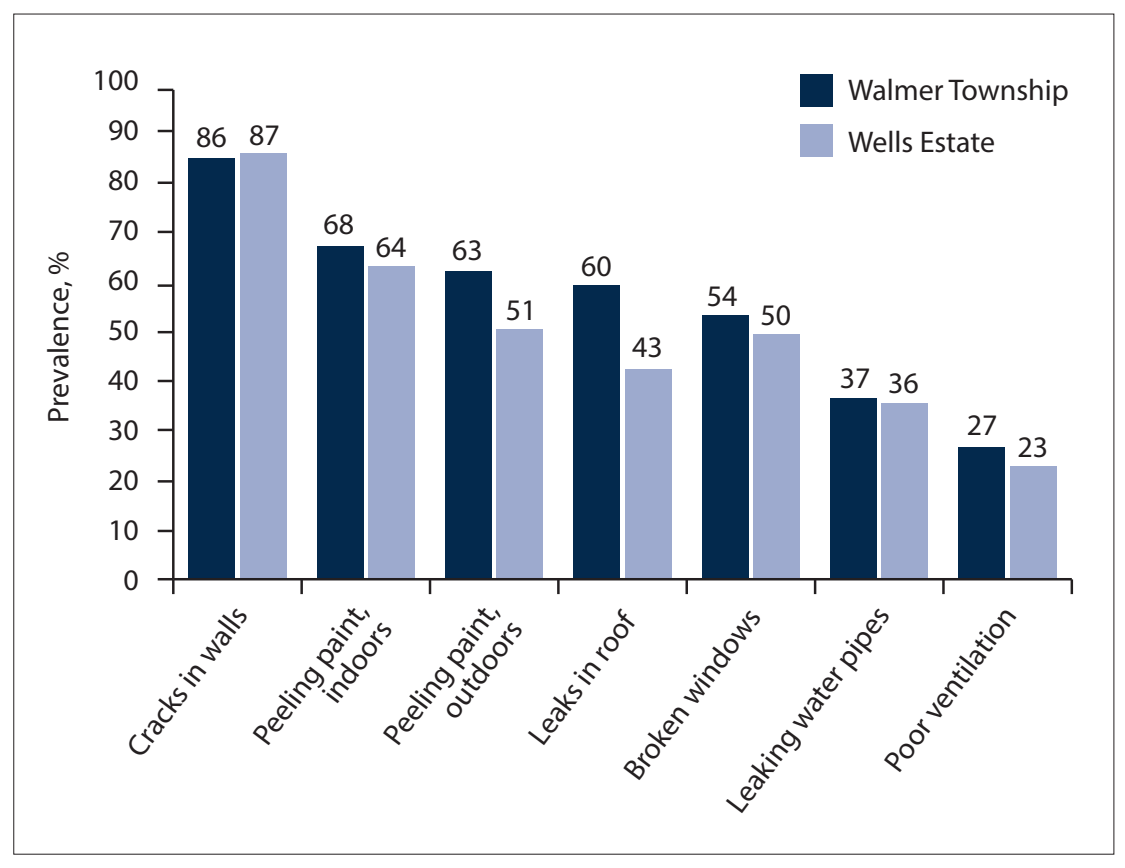

Fig. 4. Structural integrity of dwellings in Walmer Township and Wells Estate.

have been associated with the emission of pollutants such as carbon monoxide, particulate matter and black carbon, ${ }^{[17,18]}$ as well as poor scores on assessments of subjective wellbeing among people living beneath the aircraft flight paths. ${ }^{[19]}$ An SA study associated living in close proximity to an airport with elevations in hearing thresholds. ${ }^{[20]}$ Given the very short distance between Walmer Township and the local airport, more comprehensive investigations of the health risks, including hearing and cardiac effects, associated with air pollution and noise are warranted.

Holistic consideration of the findings of this study point to multiple lost oppor- tunities for the prevention of ill health, in terms of housing quality, poverty, livelihoods and the proximity of human settlements to point sources of pollution. Together with local health departments, non-health sectors such as urban planners, the human settlement sector, trade and industry, finance and the housing sector are in powerful positions to prevent ill health, in some instances in a more compelling and cost-effective manner than the health sector. Non-health sectors need to recognise that they are a health force to be reckoned with, and to take ownership of and exploit the opportunities they hold to prevent disease, save lives and build healthy communities, especially during this era of climate change. Failure to do so ultimately translates to potential acts of environmental injustice, heavy burdens of ill health among the most vulnerable in our unequal society, and a dimming of prospects of kick-starting the stagnant SA economy.

\section{Study limitations}

In this cross-sectional study, a snapshot has been provided of the situation at the time of fieldwork, and causal links between environmental exposures/living conditions and health status cannot be drawn. The sample size was relatively small, and the study findings cannot be extrapolated to other settings. 
Table 3. Logistic regression with ORs showing the relationship between exposures and infectious respiratory health outcomes

\begin{tabular}{|c|c|c|c|c|c|c|}
\hline \multirow[b]{2}{*}{ Variable } & \multicolumn{3}{|c|}{ LRTIs } & \multicolumn{3}{|c|}{ URTIs } \\
\hline & Crude OR & $95 \% \mathrm{CI}$ & $p$-value & Crude OR & $95 \% \mathrm{CI}$ & $p$-value \\
\hline Income $<$ ZAR1 000 & 0.791 & $0.312-1.014$ & $0.056^{*}$ & 0.845 & $0.458-1.556$ & 0.588 \\
\hline Smoking in household & 1.168 & $0.6379-2.140$ & 0.614 & 1.746 & $0.905-3.370$ & 0.097 \\
\hline \multirow[t]{2}{*}{ Child $<5$ years in household } & 8.514 & $4.103-17.669$ & $<0.001^{\star *}$ & 1.978 & $1.028-3.806$ & $0.041^{*}$ \\
\hline & aOR 7.292 & $3.460-15.369$ & $<0.001^{\star *}$ & aOR 1.703 & $0.826-3.513$ & 0.150 \\
\hline $\begin{array}{l}\text { Head of household has secondary or } \\
\text { higher education }\end{array}$ & 1.28 & $0.652-2.498$ & 0.476 & 0.814 & $0.407-1.629$ & 0.561 \\
\hline \multirow[t]{2}{*}{ Increased dust in house } & 1.145 & $0.611-2.148$ & 0.672 & 2.073 & $1.083-3.969$ & $0.028^{*}$ \\
\hline & & & & aOR 1.034 & $0.482-2.218$ & 0.931 \\
\hline Mould or fungus in the dwelling & 1.08 & $0.599-1.949$ & 0.796 & 1.153 & $0.621-2.139$ & 0.652 \\
\hline Damp in the dwelling & 1.02 & $0.572-1.844$ & 0.929 & 1.813 & $0.968-3.395$ & 0.063 \\
\hline \multirow[t]{2}{*}{ Cracks in walls } & 3.01 & $1.225-7.385$ & $0.016^{*}$ & 2.890 & $1.224-6.827$ & $0.016^{*}$ \\
\hline & aOR 2.524 & $0.914-6.972$ & 0.074 & aOR 2.188 & $0.852-5.622$ & 0.104 \\
\hline Leaking pipes & 1.30 & $0.707-2.399$ & 0.397 & 1.171 & $0.616-2.228$ & 0.629 \\
\hline \multirow[t]{2}{*}{ Bad odours in the neighbourhood } & 0.821 & $0.449-1.502$ & 0.522 & 2.393 & $1.273-4.497$ & $0.007^{*}$ \\
\hline & & & & aOR 1.906 & $0.922-3.940$ & 0.082 \\
\hline Poor ventilation in the dwelling & 0.917 & $0.466-1.803$ & 0.802 & 0.709 & $0.354-1.423$ & 0.334 \\
\hline \multirow[t]{2}{*}{ Air pollution in the neighbourhood } & 1.324 & $0.728-2.409$ & 0.358 & 2.723 & $1.447-5.128$ & $0.002^{*}$ \\
\hline & & & & aOR 2.031 & $0.997-4.135$ & $0.051^{*}$ \\
\hline \multirow[t]{2}{*}{ Overcrowding in dwelling } & 2.853 & $1.411-5.768$ & $0.004^{*}$ & 2.699 & $1.244-5.857$ & $0.012^{*}$ \\
\hline & aOR 2.018 & $0.923-4.412$ & 0.078 & aOR 1.841 & $0.740-4.581$ & 0.189 \\
\hline Cottage industry & 2.33 & $0.795-6.834$ & 0.123 & 1.409 & $0.479-4.149$ & 0.533 \\
\hline \multirow[t]{2}{*}{ Overcrowding in neighbourhood } & 1.331 & $0.736-1.587$ & 0.345 & 2.189 & $1.145-4.184$ & $0.018^{\star}$ \\
\hline & & & & aOR 1.311 & $0.605-2.839$ & 0.605 \\
\hline
\end{tabular}

\section{Conclusions}

This study highlights the triple threat of socioenvironmental hazards faced by the communities of Walmer Township and Wells Estate: (i) poverty; (ii) poor housing quality; and (iii) the lack of an effective buffer zone between human settlements and point sources of pollution associated with a range of harmful substances. These preventable environmental health hazards may be associated with a burden of ill health and mortality that is preventable, and in which regard non-health sectors, such as planners, housing departments, trade/industry and finance, have a powerful preventive role to play.

Declaration. None.

Acknowledgements. We thank the environmental health students of Nelson Mandela University for their role in conducting fieldwork, and the residents of Walmer Township and Wells Estate who participated in the study.

Author contributions. AM and NN conceptualised and designed the study. NN analysed the data. JT drafted the paper with participation and constructive discussion from AM, NN, CS and RS.

Funding. The study was made possible by funding from the South African Medical Research Council and the Nelson Mandela University Teaching and Development Fund.

Conflicts of interest. None.

1. World Health Organization. WHO housing and health guidelines: Recommendations to promote healthy housing for a sustainable and equitable future. 2018. https:/www who.int/sustainable-development/ publications/housing-health-guidelines/en/ (accessed 8 January 2020).

2. Bonnefoy X. Inadequate housing and health: An overview. Int J Environ Pollution 2007;30(3/4):411-429. 2. Bonnefoy X. Inadequate housing and heal

3. Al-Wahaibi A, Zeka A. Health impacts from living near a major industrial park in Oman. BMC Public Health 2015;15(1):524. https://doi.org/10.1186/s12889-015-1866-3
4. García-Pérez J, López-Abente G, Gómez-Barroso D, et al. Childhood leukemia and residential proximity to industrial urban sites. Environ Res 2015;140:542-553. https://doi.org/10.1016/j.envres.2015.05.014

5. Diawara M, Shrestha S, Carsella J, Farmer S. Smelting remains a public health risk nearly a century later: A case study in Pueblo, Colorado, USA. Int J Environ Res Public Health 2018;15(5):932. https://doi. A case study in Pueblo, Color
org $/ 10.3390 /$ ijerph 15050932

6. Marmot M, Bell R. Fair society, healthy lives. Public Health 2012;126(Suppl 1):S4-S10. https://doi org/10.1016/j.puhe.2012.05.014

Statistics South Africa. Poverty trends in South Africa: An examination of absolute poverty between 2006 and 2015. Media release, 22 August 2017. http://www.statssa.gov.za/?p=10341 (accessed 21 November and 2015. Media release, 22 August 2017. http://www.statssa.gov.za/?p=10341 (accessed 21 Novembe
2017).

8. Census 2011. Port Elizabeth and sub areas. http://census2011.adrianfrith.com/place/299007 (accessed 18 July 2018).

Coega Development Corporation, E-Album, booklets 2015 - 2016. http://extranet.coega.co.za/Coega_e Album/Coega_Profile_Booklet_2014-2015/index.html (accessed 13 September 2016).

10. DeMoss TL. Building houses or creating homes: Housing development programs and quality of life in Port Elizabeth, South Africa. DPhil dissertation. Washington, DC: American University, 2012. http:/ auislandora.wrlc.org/islandora/object/thesesdissertations\%3A86 (accessed 8 September 2016).

11. Coastal and Environmental Services. The subsequent environmental impact report for the proposed Por of Ngqura. Appendix E: A forensic audit of the relocation process and impacts of the proposed Por of Ngqura. Coega Development Corporation, September 2001. http://fred.csir.co.za/project/CIP_EIA/ pages/Subsequent_Port_EIR.PDF (accessed 27 September 2016).

12. Statistics South Africa. Quarterly labour force survey, Quarter 1: 2016. Statistical release P0211. Pretoria Stats SA, July 2016. http://www.statssa.gov.za/publications/P0211/P02111stQuarter2016.pdf (accessed 15 March 2017).

3. Marmot M, Allen JJ. Social determinants of health equity. Am J Public Health 2014;104(S4):S517-S519. https://doi.org/10.2105/ajph.2014.302200

4. Raphael D, Bryant T, Mikkonen J, Raphael A. Social Determinants of Health: The Canadian Facts. 2nd ed. Oshawa: Ontario Tech University Faculty of Health Sciences and Toronto: York University School of Health Policy and Management, 2020. http://www.thecanadianfacts.org/ (accessed 13 March 2019).

15. Teare J, Kootbodien T, Naicker N, Mathee A. The extent, nature and environmental health implications of cottage industries in Johannesburg, South Africa. Int J Environ Res Public Health 2015;12(2):1894-1901 https://doi.org/10.3390/ijerph120201894

16. Marmot M. Social determinants of health inequalities. Lancet 2005;365(9464):1099-1104. https://doi. org/10.1016/S0140-6736(05)71146-6

7. Schlenker W, Walker WR. Airports, air pollution, and contemporaneous health. Review Econ Stud 2016;83(2):768-809. https://doi.org/10.1093/restud/rdv043

18. Stettler M Eastham S, Barrett S. Air quality and public health impacts of UK airports. Part I: Emissions. Stettler M Eastham S, Barrett S. Air quality and public health impacts of UK airports. P
Atmos Environ 2011;45(31):5415-5424. https://doi.org/10.1016/j.atmosenv.2011.07.012

19. Las RN, Fulw D. Ling with a d Lawn RN, Fujwara D. Living with aircraft noise. Aliport proximity, aviation noise and subjective wellbeing in England. Transp Res Part D Transp Environ 2016;42:104-118. https://doi.org/10.1016/j
trd.2015.11.002

20. Pillay D, Archary K, Panday S. A preliminary study of the effects of aircraft noise on families who reside in close proximity to an airport. S Afr Fam Pract 2011;53(4):361-365. https://doi.org/10.1080/2078620 4.2011 .10874115

Accepted 3 June 2020. 